\title{
Trinta minutos que mudam a vida: Teste Rápido Anti-HIV Diagnóstico para parturientes e acesso ao pré-natal
}

Diretrizes governamentais para redução da transmissão vertical do HIV incluem o Teste Rápido Anti-HIV Diagnóstico às mulheres. Objetivou-se refletir sobre conflitos éticos vinculados à realização do teste durante o parto, utilizando-se a Bioética Principialista e a Bioética Feminista. Trinta minutos separam o oferecimento do exame e o resultado, mudando a vida completamente. Parturientes admitidas sem o anti-HIV no pré-natal refletem a dificuldade no acesso aos serviços de saúde. Falhas organizacionais no sistema de referência e contra referência dificultam o acompanhamento de soropositivas e bebês expostos ao vírus após a alta. Profissionais capacitados podem oferecer atenção de qualidade minimizando a vulnerabilidade mãe-filho.

Descritores: Bioética, Vulnerabilidade, Acesso aos Serviços de Saúde, Cuidado Perinatal, Sorodiagnóstico da Aids.

\section{Thirty minutes life change: Anti-HIV rapid test diagnosis for pregnant women and access to prenatal care}

Governmental guidelines to reduce vertical transmission of HIV include the Quick Test Anti-HIV Diagnosis women. Study aimed to reflect on ethical conflicts related to testing during labor, using principlist Bioethics and Feminist Bioethics. Thirty minutes separating the offering of the examination and the result, changing their lives completely. Pregnant women admitted without anti-HIV prenatal reflect the difficulty in accessing health services. Organizational failures in the system of reference and cross reference complicate follow up and seropositive babies exposed to the virus after discharge. Trained professionals can provide quality care while minimizing the vulnerability mother-son.

Descritores: Bioethics, Vulnerability, Access to Health Care, Perinatal Care, Serodiagnosis of AIDS.

\section{Treinta minutos que cambian la vida: Anti-HIV prueba rápida de diagnóstico para las mujeres embarazadas y el acceso a la atención prenatal} Directrices gubernamentales para reducir la transmisión vertical del HIV incluyen las pruebas rápidas contra el HIV Diagnóstico a las mujeres. El objetivo era reflexionar sobre los conflictos éticos relacionados con las pruebas durante el parto, con la Bioética y Bioética principialista feministas. Treinta minutos que separan la oferta del examen y el resultado, cambiando sus vidas por completo. Las mujeres embarazadas admitidas sin anti-HIV prenatal reflejan la dificultad en el acceso a servicios de salud. Fallas de organización en el sistema de referencia y de referencia cruzada dificultan el seguimiento de bebés y seropositivos expuestos al virus después del alta. Profesionales entrenados pueden proporcionar una calidad de atención y reducir al mínimo la vulnerabilidad madre-hijo. Descritores: Bioética, Vulnerabilidad, acceso a la salud, la atención perinatal, serodiagnóstico del SIDA.

\section{INTRODUÇÃO}

A epidemia do HIV/Aids tornou mandatória a elaboração e implementação de políticas públicas voltadas para promoção, prevenção, diagnóstico, tratamento, acesso Iaos serviços e observação dos direitos humanos. $\mathrm{O}$ programa brasileiro é considerado mundialmente exitoso. Visa reduzir a transmissão do HIV e melhorar a qualidade de vida das pessoas infectadas.

A transmissão vertical do HIV (TV-HIV) requer atenção da política de enfrentamento da Aids, incluindo-se a eticidade das questões envolvendo mulheres e crianças. Os cuidados perinatais são prerrogativa legal, porém a vulnerabilidade de muitas mulheres compromete o acesso aos serviços de saúde ${ }^{(1)}$. A TV-HIV é a principal causa de Aids em menores de 13 anos de idade. A incidência chega a $25,5 \%$ dessa população, sem medidas profiláticas. O Protocolo 076 do Aids Clinical Trial Group - quimioprofilaxia com AZT, não-amamentação, uso da fórmula láctea - reduz esses índices em $67,5 \%$. Ressalta-se que no trabalho de parto e no parto ocorrem $65 \%$ dos casos de TV-HIV, e a amamentação representa um risco adicional de 7\% a $22 \%$ na transmissão ${ }^{(2-4)}$.

As diretrizes prioritárias referentes à TV-HIV foram definidas pelo Programa Nacional de DST e Aids, posteriormente denominado Departamento Nacional de DST e Aids (DN-DST/ Aids), do Ministério da Saúde (MS). Em 2002, instituiu-se o Projeto Nascer-Maternidades, ampliado em 2007 e adotado pelo Sistema Único de Saúde (SUS) ${ }^{(2)}$.

O projeto busca diminuir a TV-HIV, a morbimortalidade da sífilis congênita e melhorar a assistência perinatal. Está

1 Enfermeira. Mestre em Educação; Doutoranda no Programa de Pós-Graduação em Enfermagem da UnB. Docente da Escola Superior de Ciências da Saúde (ESCS/SES-DF). Email: onatil@gmail.com

2 Enfermeira. Doutora em Ciências da Saúde (Bioética). Professora Titular da Universidade de Brasília. Coordenadora do Programa de Pós-Graduação em Enfermagem da UnB. 3 Enfermeira. Doutora em Ciências da Saúde (Bioética). Professora Adjunta do Departamento de Enfermagem da Faculdade de Ciências da Saúde da Universidade de Brasília. 
Silva O, Guilhem D, Bampi LNS. Trinta minutos que mudam a vida:Teste Rápido Anti-HIV Diagnóstico para parturientes e acesso ao pré-natal

implantado em maternidades do SUS - próprias e conveniadas - nos municípios que atendem mais de 500 partos/ano. Dado importante relaciona-se à cobertura inferior à meta dos testes anti-HIV no pré-natal ${ }^{(5,6)}$.

Ações pró-redução da TV-HIV pressupõem o oferecimento de suporte para atendimento à gestante soropositiva e seu recém-nascido, incluindo o diagnóstico sorológico na gravidez, o que é um direito da gestante/parturiente ${ }^{(2,5,7)}$. O teste anti-HIV - com aconselhamento e consentimento - deve ser oferecido na primeira consulta pré-natal, repetido no início do terceiro trimestre, utilizando-se testes rápidos quando necessário ${ }^{(2)}$. Essas estratégias visam proteger as mulheres, ampliar o diagnóstico e fortalecer parcerias.

Ainda são restritos os estudos sobre a TV-HIV abordando conflitos éticos, complexidade da situação e vulnerabilidade vivenciada pela gestante durante a testagem rápida anti-HIV no parto. Há escassez de dados sobre os impactos éticos e psicossociais que emergem da testagem rápida anti-HIV e a revelação diagnóstica para parturientes/puérperas nesse momento de vulnerabilidade. A abordagem ética do tema oferece benefícios e assegura a integridade humana, significando ato de cuidado e proteção para mulheres e bebês.

Considerando essas questões, este artigo objetiva refletir sobre os conflitos éticos relacionados à realização do Teste Rápido Anti-HIV Diagnóstico (TRAHIV-Diagnóstico) no momento do parto, o que concorre para sedimentar a vulnerabilidade experimentada por parturientes e puérperas. Menciona-se também que a admissão na maternidade de mulheres sem resultado do exame anti-HIV no pré-natal reflete a dificuldade de acesso aos serviços de saúde.

\section{APROXIMAÇÃO AO TEMA}

\section{Transmissão vertical do HIV}

A TV-HIV ocorre em $65 \%$ dos casos durante o trabalho de parto e no parto e $35 \%$ intraútero, principalmente no final da gestação. A amamentação responde por $7 \%$ a $22 \%$ da transmissão, renovando-se a cada mamada. Aumenta em 30\% quando a infecção materna ocorre nesse período. $\mathrm{O}$ aleitamento materno e o aleitamento cruzado são contraindicados ${ }^{(5,7)}$.

A TV-HIV relaciona-se a diversos fatores maternos como: carga viral, genótipo e fenótipo viral, estado clínico, nutricional e imunológico, uso de drogas, via de parto, hemorragia intraparto, entre outros. Existem também fatores intrínsecos ao recém-nascido: prematuridade, baixo peso ao nascer e aleitamento materno. A redução da TV-HIV pode baixar entre zero e 2\%, quando utilizados antirretrovirais, adoção de cesariana eletiva e carga viral menor do que 1.000 cópias $/ \mathrm{ml}$, ao final da gestação ${ }^{(4,7)}$.

\section{Teste Rápido Anti-HIV Diagnóstico}

Os testes rápidos anti-HIV possuem metodologia simples, produzem resultado em no máximo 30 minutos e apresentam sensibilidade e especificidade similares ao ELISA e Westem $\operatorname{Blot}^{(7-9)}$.

A Portaria MS no 34/05 regulamentou o uso desse exame em situações especiais, pois o acesso ao status sorológico e ao diagnóstico precoce da infecção interrompem a cadeia transmissora ${ }^{(8-10)}$. Posteriormente, o DN-DST e Aids incluiu esse exame na atenção às parturientes/puérperas sem resultado no terceiro trimestre gestacional e diagnóstico negativo anterior. Trata-se de medida importante para reavaliação diagnóstica tendo como vantagens o resultado imediato e a redução das perdas pelo não retorno ${ }^{(4,5,11)}$.

O acesso ao teste é direito para a gestante/parturiente, mas precisa atender a critérios de voluntariedade e confidencialidade. O teste rápido é a última chance de intervenção profilática emergencial, permitindo conhecer o status sorológico materno no momento do parto e adotar medidas protetoras ao recém--nascido.

\section{Revelação diagnóstica de soropositividade no parto: conflitos éticos e vulnerabilidade materno-infantil}

O TRAHIV-Diagnóstico apresenta vantagens operacionais inequívocas, mas pode concorrer para cristalizar a vulnerabilidade da mulher soropositiva pelos desdobramentos dessa revelação em momento delicado como o trabalho de parto. A contraposição entre sentimentos e possibilidades, entre a nova vida e o conhecimento de possuir uma doença potencialmente fatal, fragiliza a mulher e desafia o sistema de saúde.

Embora intimamente relacionados, os conceitos de ética e moral representam diferentes vertentes. Tradicionalmente, ética é considerada ferramenta analítica - incluindo teorias, valores e princípios - permitindo reflexão e indicando caminhos para solucionar conflitos reais ${ }^{(12)}$. Por outro lado, a moral reflete essa realidade a partir de normas, costumes e posturas compartilhadas pela sociedade, considerando-se que a condição humana é mutável no tempo e espaço, exigindo abordagem multidimensional das situações encontradas ${ }^{(13)}$.

Partindo da leitura de cada pessoa dessa herança cultural-normativa, torna-se possível traduzir esses códigos em posturas, atitudes e comportamentos - as moralidades adotados pelos indivíduos ou grupos sociais. Esse processo de tradução é singular, pois no encontro entre as moralidades emergem conflitos interpessoais e coletivos ${ }^{(14)}$. Exemplo dessa tensão ocorre na relação profissional-paciente, quando o profissional considera sua a prerrogativa de decidir sobre qual o melhor tratamento ao paciente, desconsiderando sua opinião.

Para além de definições e conceitos, o exercício ético na prática clínica significa respeito pela dignidade humana. Esse respeito compreende aspectos como a capacidade de autodeterminação consciente e responsável pela vida e autonomia nas decisões relacionadas à saúde e bemestar humanos ${ }^{(15)}$. No cenário de atenção à gestante, o oferecimento do TRAHIV-Diagnóstico no momento da parturição pode não ser bem recebido pela mulher, surgindo conflitos com os profissionais que tradicionalmente se posicionam ao lado do nascituro.

Torna-se necessário ampliar o enfoque analítico sobre esta questão, pois inexistem respostas simples para enfrentar conflitos do encontro entre as moralidades. Os princípios tradicionalmente relacionados às correntes teóricas da bioética 
-aTeoriadosPrincípios-auxiliamnessa tarefa.Resumidamente, os quatro princípios apontam para preceitos amplamente aceitos na contemporaneidade: 1) autonomia: cada pessoa tem liberdade para agir conforme sua autodeterminação; 2) beneficência:fazer obem, buscando maximizar os benefícios; 3) não-maleficência: evitar fazer o mal e minimizar os riscos; 4) justiça: valores sociais que favorecem a justiça distributiva e a equidade ${ }^{(16)}$.

Posteriormente, as teorias críticas na bioética - entre as quais a Teoria de Inspiração Feminista - ampliaram o leque de atenção para situações tradicionalmente silenciadas, dando visibilidade às pessoas excluídas dos estudos éticos: crianças, mulheres, pobres, deficientes e outros grupos. Evidenciou que a mediação dos conflitos morais em contextos de desigualdade social não pode ser solucionada por princípios absolutos. Deveriam ser incluídos "...mecanismos éticos de intervenção frente a todos os tipos de desigualdade", adotando-se a defesa de princípios compensatórios da vulnerabilidade moral e social." $\left.{ }^{\prime \prime} 7,18\right)$.

O conceito de vulnerabilidade tem sido amplamente utilizado no contexto do HIV/Aids, pois a infecção supera o modelo epidemiológico de risco. Todas as pessoas são vulneráveis, apresentam situações de fragilidade constitutivas da condição humana, sendo que determinações sociais aumentam ou diminuem a suscetibilidade dos indivíduos ${ }^{(19)}$.

Partiu-se da seguinte tipificação de vulnerabilidade: vulnerabilidade extrínseca: gerada por fatores externos como falta de poder socioeconômico, baixa escolaridade, políticas públicas inadequadas/não implantadas ou falta de acesso, entre outros; vulnerabilidade intrínseca: ocasionada por fatores intrínsecos às pessoas como raça, escolaridade, doença mental ou grave, extremos etários (crianças e idosos), mulheres e gestantes ${ }^{(20)}$.

Emergem duas vertentes conceituais: vulnerabilidade circunstancial: situações de exposição a determinado evento ou circunstância, referindo-se a exposição passageira à infecção, por exemplo, pessoas submetidas a transfusões sanguíneas; vulnerabilidade permanente: exposição constante a alguma situação ou conjuntura, relacionando-se a situação persistente de exposição ao vírus, como uso de drogas injetáveis ou sexo desprotegido ${ }^{(18,21)}$.

A vulnerabilidade pode ser compreendida como um "...construto multifacetado que resulta de uma conjunção de fatores individuais (biológicos, cognitivos e comportamentais), programáticos (programas de prevenção, educação, controle e assistência, bem como vontade política), sociais (relacionados às questões econômicas e sociais) e culturais (submissão a padrões e crenças morais, hierarquias, relações de poder, questões de gênero), interdependentes e mutuamente influenciáveis, assumindo pesos e significados diversos que variam no decorrer do tempo e determinam o grau de susceptibilidade de indivíduos e grupos em relação a questões de saúde." (18,21). Compreender essas diferentes nuanças conceituais auxilia na discussão do oferecimento do TRAHIV-Diagnóstico no período perinatal.

A mulher soropositiva vivencia a vulnerabilidade de forma diferente daquela que desconhece seu status sorológico. Ainda que a soropositividade na gestação seja impactante para a pessoa e a família, o acesso ao serviço de saúde permite minimizar a TV-HIV e direcionar cuidados específicos para a saúde materna segundo protocolos preestabelecidos ${ }^{(22)}$.

Quando a parturiente chega à maternidade sem o resultado do exame, a experiência da vulnerabilidade pode ser amplificada considerando-se diferentes aspectos: ausência de acesso a serviços de pré-natal; enfrentamento do diagnóstico de uma doença até o momento incurável e sua transmissão ao filho; premência para decidir se realiza ou não o TRAHIV-Diagnóstico; revelação diagnóstica forçada e consequências como preconceito e discriminação; desinformação ou incompreensão sobre as orientações fornecidas em momento delicado para a mulher. Ocorre a sedimentação de distintas vertentes da vulnerabilidade revelando a fragilidade não apenas pessoal, mas das políticas que não conseguem alcançar e proteger essas mulheres.

A revelação diagnóstica requer apoio de profissionais capacitados que realizem o aconselhamento requerido, ajudando a parturiente a encontrar meios de enfrentar o diagnóstico. Simultaneamente, deverão ser desenvolvidas estratégias referentes ao sigilo sobre sua soropositividade ${ }^{(8)}$.

Nesse cenário, um aspecto que contribui para a sedimentação da vulnerabilidade maternoinfantil refere-se à equipe de saúde que nem sempre está capacitada para fornecer o suporte para essa mulher. Preconceitos e moralidades acompanham os profissionais no desenvolvimento da prática profissional, dificultando assistência digna e qualificada, direito das usuárias do sistema. Qualquer barreira no estabelecimento do vínculo profissionalusuária gera consequências inequívocas para a pessoa incapaz de defender seus próprios interesses ${ }^{(18)}$.

A organização dos serviços de saúde e a assistência às mulheres soropositivas e seus recém-nascidos incide sobre a vulnerabilidade materno-infantil, sendo um dos componentes de vulnerabilidade programática, especialmente quando existem falhas na rede assistencial e no sistema de referência/ contrarreferência.

Estudo realizado em 17 maternidades de quatro regiões brasileiras apontou problemas no acesso ao diagnóstico, na atenção ao pré-natal e no acompanhamento pós-natal|(23). Foram incluídas 1.475 mulheres infectadas e seus recém-nascidos. Os resultados demonstraram que: $10 \%$ não tiveram acesso ao pré-natal; $13 \%$ das parturientes realizaram seis consultas, mínimo preconizado pelo MS para gestantes sem risco; pequena minoria - $1 \%$ dos casos - realizou 10 ou mais 
consultas, o número necessário para esse grupo de gestantes ${ }^{(23)}$. Foram apontadas lacunas no acesso ao diagnóstico das crianças, sendo que apenas 771 (52\%) receberam o diagnóstico. Houve porcentagem expressiva de perda no seguimento de 676 crianças $(45,83 \%)^{(23)}$.

\section{DISCUSSÃO}

A realização do teste anti-HIV, acompanhando de aconselhamento, representa importante estratégia de cuidados perinatais e minimiza a vulnerabilidade que envolve a gestante e a criança expostas ao vírus. A escuta qualificada facilita o vínculo entre a equipe de saúde e a mulher. Trata-se de momento ímpar para identificar e minimizar conflitos e situações que ocasionam fragilidades. O profissional pode avaliar vulnerabilidades relacionadas ao HIV a outras esferas da vida da gestante, como a possibilidade de contrair infecções, e a preparação para o diagnóstico. Podem ser incluídas medidas preventivas relacionadas aos parceiros sexuais e ao uso de drogas ${ }^{(3,5)}$.

Nas diretrizes prioritárias pró-redução da TV-HIV, menciona-se que a testagem anti-HIV deve ser oferecida desde a primeira consulta do pré-natal. A gestante tem direito de realizar três exames, mas distintos fatores concorrem para a inacessibilidade das mulheres ao pré-natal, sendo submetidas ao teste apenas no processo de parturição(1-10). Essa situação ocasiona lacunas no acompanhamento qualificado à soropositiva e ao bebê exposto ao HIV. Políticas protetoras carecem de mecanismos que garantam cobertura de serviços, aumentando a vulnerabilidade maternoinfantil.

Estudo sentinela conduzido no Brasil analisou a taxa de prevalência e cobertura do teste anti-HIV no pré-natal ${ }^{(24)}$. Participaram 16.158 mulheres e, conforme os resultados, $62,3 \%$ realizaram o exame durante a gravidez. Observou-se nas regiões Nordeste e Norte menor cobertura (40,6 e 46\%), no Sudeste e Centro-Oeste cobertura de 73,7 e $69,9 \%$ e a Região Sul alcançou o maior score: $85 \%{ }^{(24)}$. Esse estudo tem importância epidemiológica relacionada às ações pró-redução da TV-HIV, desvelando desigualdades provenientes das lacunas na cobertura do teste anti-HIV na gestação. Emergiram dados importantes quanto às vulnerabilidades das mulheres não testadas no pré-natal, representadas pelas moradoras das regiões Nordeste e Norte.

Dados epidemiológicos analisados pelo MS de 2000 a 2009, notificação de 54.218 casos de infecção pelo HIV em gestantes, demonstraram que as maiores taxas ocorriam em mulheres pertencentes à faixa etária entre 20 e 29 anos e com 4 a 11 anos de escolaridade ${ }^{(25)}$.

O princípio da justiça - representado pela equidade -, tão caro à política de saúde brasileira, encontra-se inacessível para algumas mulheres que, em condições vulneráveis, submetem-se ao TRAHIV-Diagnóstico durante o parto, porque atendem ao critério denominado "situações excepcionais" $(16,17,23)$.

A rede básica tem buscado atender as diretrizes estabelecidas para a prevenção da TV-HIV pelo acesso aos serviços. O aconselhamento deve ser oferecido nos períodos pré-teste e pós-teste do exame anti-HIV. Embora o aconselhamento não se reduza a esses períodos, nem sempre as informações oferecidas pela equipe de saúde são suficientes ou compreensíveis para a mulher tomar decisão esclarecida e autônoma e submeter-se ao exame ${ }^{(18,21)}$.

Esses aspectos são importantes, mas os profissionais direcionam maior atenção ao aconselhamento do resultado sorológico positivo. Nessa situação, é oferecido suporte para o enfrentamento do impacto que o diagnóstico imprime na vida das mulheres. A segurança de sigilo demonstra respeito ao seu posicionamento sobre o momento e as pessoas com as quais deseja compartilhar a soropositividade. São fornecidas informações sobre o significado da infecção, a diferença entre ser portador do vírus e da Aids, e as medidas profiláticas como a terapia antirretroviral na gravidez, o AZT injetável no parto e o AZT oral para o bebê ${ }^{(4,5)}$. O encaminhamento ao prénatal referenciado às portadoras do vírus tem caráter prioritário.

Nessa situação delicada é possível intervir precocemente objetivando minimizar a vulnerabilidade da díade mãebebê. O outro lado da moeda - o acesso ao TRAHIV-Diagnóstico apenas na parturição - merece reflexão especial. É uma medida paliativa, um benefício tardio, muitas vezes imposto e que nem sempre soluciona a situação de saúde instalada. A realização desse exame representa uma oportunidade de conhecer o status sorológico feminino e intervir em benefício do bebê.

Receber uma má notícia no momento em que a mulher encontra-se vulnerável e fragilizada requer suporte especializado. Trinta minutos separam o oferecimento do exame e a divulgação do resultado. Trinta minutos mudam a vida, pois em caráter emergencial a mulher recebe o diagnóstico positivo para o HIV. Nessa situação é impossível falar em exercício da autonomia, em decisão livre e esclarecida. Ao contrário, a parturiente está no grupo especial: pessoas com autonomia reduzida(26). Ainda assim, agente detentor dos atributos de liberdade e dignidade. Esse é um cenário extremamente delicado do qual emergem conflitos de difícil mediação moral: vida e morte passam a coexistir e impregnam a vivência dessa mulher-mãe e do bebê que está chegando. A equipe precisa estar preparada para fornecer aconselhamento e apoio emocional necessário nesse momento.

\section{CONSIDERAÇÕES FINAIS}

A implantação do TRAHIV-Diagnóstico nas maternidades brasileiras obedece às estratégias do MS para redução da TV- 
HIV. É uma intervenção importante para ampliar e garantir o acesso das mulheres/parturientes ao diagnóstico resolutivo. Para muitas mulheres, contudo, o acesso ao pré-natal e ao exame representa uma realidade distante. Muitas delas são submetidas ao teste no parto, em caráter emergencial. Embora seja um procedimento necessário para solucionar as lacunas mencionadas, sua oferta suscita conflitos éticos e estresse materno-familiar frente à soropositividade.

Os princípios bioéticos da autonomia, não maleficência, beneficência e justiça são ferramentas analíticas dessa situação, mas a complexidade que circunda o TRHIV-Diagnóstico e o possível resultado positivo transcende a linearidade analítica. Falta introduzir nesse cenário outros conceitos e teorias ampliando a discussão sobre desigualdade social e moral vivenciada pelas mulheres.

Avulnerabilidadedaparturiente/puérperaéumdoselementos que contribui para a autonomia diminuída. Os profissionais de saúde precisam ampliar a reflexão sobre essa situação evitando abuso de poder e hierarquização da relação profissional-paciente. É preciso garantir que as mulheres tenham seus direitos e dignidade respeitados, capacitando-as para enfrentar a soropositividade que ultrapassa a esfera da subjetividade e se reflete no recém-nascido, nos familiares e no entorno social.

\section{Referências}

1. Costa AM, Guilhem D, Walter MIMT. Atendimento a gestantes no Sistema Único de Saúde. Rev Saúde Pública. 2005;39(5):769-74.

2. Ministério da Saúde (BR). Coordenação Nacional de DST e Aids. Projeto nascer. Brasilia: Ministério da Saúde; 2003.

3. Ministério da Saúde (BR). Portaria n 1.071/GM de 09 de julho de 2003. Dispõe sobre o leite artificial [Internet]. [citado 2011 Nov 26]. Disponível em: http:// dtr2001.saude.gov.br/sas/PORTARIAS/Port2003/GM/GM-1071.htm.

4. Ministério da Saúde (BR). Recomendações para profilaxia da transmissão vertical do HIV e terapia antirretroviral em gestantes. Brasília: Ministério da Saúde; 2006.

5. Ministério da Saúde (BR). Plano operacional para redução da transmissão vertical do HIV e da sífilis. Brasília: Ministério da Saúde; 2007.

6. Carneiro AJS, Coelho EAC. Aconselhamento na testagem anti-HIV no ciclo gravídico-puerperal: o olhar da integralidade. Ciênc Saúde Coletiva. 2010;15(1):1217-26.

7. Ministério da Saúde (BR). Protocolo para a prevenção de transmissão vertical de HIV e sífilis: manual de bolso. Brasília: Ministério da Saúde; 2007.

8. Silva O, Tavares LHL, Paz LC. As atuações do enfermeiro relacionadas ao teste rápido anti-HIV diagnóstico: uma reflexão de interesse da enfermagem e da saúde pública. Enferm Foco. 2011;2(Supl.):58-62.

9. Ministério da Saúde (BR). Portaria n59/GM/MS de 30 de janeiro de 2003. Padroniza o conjunto de procedimentos sequenciados para detecção de anticorpos anti-HIV para diagnóstico laboratorial da infecção pelo HIV em indivíduos com idade acima de 2 anos [Internet]. [citado em 2011 Nov em 28]. Disponível em: http://pegasus.fmrp.usp.br/projeto/legislacao/Portaria\%2059\%20 de $\% 2028 \% 2001 \% 2003$.pdf.

10. Ministério da Saúde (BR). Portaria n 34 MS/SVS de 28 de julho de 2005. Regulamenta o uso de testes rápidos para diagnóstico da infecção do HIV em situações especiais [Internet]. [citado em 2011 Nov 30]. Disponível em: http:// bvsms.saude.gov.br/bvs/saudelegis/svs/2005/prt0034_28_07_2005.html. 11. Ministério da Saúde (BR). Portaria n 151 MS/SVS, de 14 de outubro de 2009. Agiliza e amplia normas para a realização de testes anti-HIV. [Internet]. [citado em 2011 Dez 10] Disponível em: http://www.aids.gov.br/sites/default/files/portaria151_2009.pdf

12. Figueiredo AM, Guilhem D. Ética e moral. INTERthesis. 2008;5:29-46.

13. Napoli RBD. Fundamentos éticos e bioéticos das resoluções sobre a ética em pesquisa no Brasil. Ethic@. 2007;6(1):75-97.
14. Guilhem D. Bioética e enfermagem: construção histórico-moral das enfermeiras. Brasilia: Working Paper; 2010.

15. Macklin R. Dignity as a useless concept. BMJ. 2003;327:1419-20.

16. Beauchamp TL, Childress JF. Princípios de ética biomédica. $4^{a}$ ed. São Paulo: Loyola; 2002.

17. Diniz D, Guilhem D. Bioética feminista: o resgate político do conceito de vulnerabilidade. Bioética. 1999;7(2):181-9.

18. Guilhem D. Escravas do risco: bioética mulheres e aids. Brasília: FINATEC/ UnB; 2005.

19. Marques Junior JS, Gomes R, Nascimento EF. Masculinidade hegemônica, vulnerabilidade e prevenção ao HIV/AIDS. Rev C S Col [Internet]. [citado em 2012 Mar 23]. Disponível em: http://www.cienciaesaudecoletiva.com.br/artigos/artigo_int.php?id_artigo=7673

20. Rogers W, Ballantyne A. Populações especiais: vulnerabilidade e proteção [Internet]. [citado em 2012 Mar 23]. Disponível em: http://www.reciis.cict.fiocruz. br/index.php/reciis/article/view/207/181

21. Guilhem $D$, Azevedo AF. Bioética e gênero: moralidades e vulnerabilidade feminina no contexto da aids. Bioética. 2008;16(2):229-40.

22. Azevedo $A F$, Guilhem D. A vulnerabilidade da gestante na situação conjugal de sorodiferença para o HIV. DST J Bras Doenças Sex Transm. 2005;17(3):189-96. 23. Szwarcwald CL, Barbosa Júnior $A$, Souza-Júnior PRB, Lemos KRV, Frias PG, Luhm KR, Holcman MM, Esteves MAP. HIV testing during pregnancy: use of secondary data to estimate test coverage and prevalence in Brazil, 2006. Braz J Infect Dis. 2008;12(3):167-72.

24. Vasconcelos ALR, Hamann EM. Por que o Brasil ainda registra elevados coeficientes de transmissão vertical do HIV? Uma avaliação da qualidade da assistência prestada a gestantes/parturientes infectadas pelo HIV e seus recémnascidos. Rev Bras Saúde Matern Infan 2005; 5(4):483-492.

25. Brasil. Ministério da Saúde. Secretaria de Vigilância em Saúde. Departamento Nacional de DST, Aids e Hepatites Virais. Boletim Epidemiológico - Aids, DST. Ano VII - $n^{\circ} 1-27^{\mathrm{a}}$ a $52^{\mathrm{a}}$ - semanas epidemiológicas - julho a dezembro de 2009 Ano VII - n० 1 - 01 a a 26a - semanas epidemiológicas - janeiro a junho de 2010. Brasília: Ministério da Saúde; 2010. [acessado 2012 mar 31]. Disponível em: http:// www.aids.gov.br/sites/default/files/anexos/publicacao/2010/45974/vers_o_final_15923.pdf.

26. Guimarães MCS, Novaes SC. Autonomia reduzida e vulnerabilidade: liberdade de decisão, diferença e desigualdade. Rev Bioét 1999; 7(2):21-24. 